\title{
Robert Rie
}

Robert Rie, professor emeritus of German language and literature at the State University College of New York at Fredonia, died unexpectedly on April 18, 1981. Born in Vienna in 1904, Rie received his doctorate in law from the University of Vienna in 1928. In 1938, following Austria's annexation by Nazi Germany, he came to the United States. He taught German, French, and Latin, as well as European history, at several universities, including Bradley University, Clark College, and St. Cloud State College, before joining the faculty of the State University College at Fredonia, New York, in 1963. There Rie continued to kindle in his students a keen interest in the German language and German literature - and coincidently an awareness of Austrian and German history and culture-long after his "official" retirement in 1975.

Rie's scholarly pursuits covered a wide diversity of subjects. He penned several books and over forty-five articles on topics ranging from the concept of an economic confederation for the Danube Basin to American copyright laws. He reserved his primary interest, however, for things Austrian, especially the history and literature of the Habsburg monarchy during its last century of existence. Of note are his many articles on the Congress of Vienna of 1815 and his book, Der Wiener Kongress und das Völkerrecht. Together with Evabeth Miller Kienast, he translated and edited the letters of Emperor Francis Joseph and Katharina Schratt. Another long-time interest of Rie's was the work of the well-known Austrian author, Stefan Zweig, and during the last years of his life he played a major role in founding an archive to house Zweig's books, letters, and other writings at the State University College at Fredonia. This collection, originally established in 1968, was expanded with the opening of the Stefan Zweig Room in 1981. In recognition of Rie's contributions to scholarship and letters, the Austrian government awarded him an honor cross in arts and sciences in 1977.

The diversity of Rie the scholar, however, was but a reflection of the character of the man. Charming, witty, and always energetic, he displayed a keen interest in his students even after their professional pursuits had taken them beyond the walls of the classroom. His personal warmth and understanding were a frequent source of encouragement to his many friends and associates. Those who knew him well will sorely miss his jovial voice, his good-natured repartee, and his positive approach to the world in which he lived. 